\title{
Penggunaan Model Problem Based Learning dalam Mengatasi Permasalahan IPA Tematik di SD
}

\author{
Sundari, $\mathbf{J S}^{\mathbf{1}}$, Yanti Fitria ${ }^{2}$ \\ ${ }^{1}$ Universitas Negeri Padang, ${ }^{2}$ Universitas Negeri Padang \\ * e-mail: sundarijamuas@gmail.com
}

\begin{abstract}
Thematic learning combines several subjects related to each other, which are combined in one learning theme. Science learning is one of the subjects related to thematic learning. This study aims to solve the problem of science learning through the Problem Based Learning model. This study used a literature study approach from journal articles and other references to strengthen the advantages of the problem-based learning model in overcoming learning problems. The results showed that problem-based learning is a model of problem-based learning that exists in real life and invites students to solve these problems. Based on the analysis of the results of research conducted by previous researchers, it can be seen that the PBL model affects students' critical thinking abilities, learning outcomes, and student process skills..
\end{abstract}

Keywords: thematic learning, science, problem based learning

\section{INTRODUCTION}

Kemajuan suatu bangsa bergantung pada sumber daya manusia (SDM). Dalam hal ini pendidikan pendidiakn memegang hal penting dalam pengembangan sumber daya manusia. Pendidikan sebagai faktor penting dalam peningkatan kualitas sumber daya manusia dan seberapa tingkat kemajuan suatu bangsa. Pendidikan yang bermutu ialah pendidiakn yang dapat melahirkan penerus-penerus bangsa yang bermutu dan di era globalisasi bisa bersaing dengan perubahan dan berkembangan yang begitu pesat.

Untuk meningkatkan kualitas pendidikan pemerintah sangat berupaya dengan meningkatkan kualitas pendidikan nasional. Peningkatan pendidikan nasional dilakukan dengan diberlakukannya Kuriulum 2013. Kurikulum 2013 merupakan kurikulum dengan menggunakan pendekatan saintifik. Dengan penekanan pada proses yang mana bersifat holistik sehingga dapat menyentuh pada cakupan yang luas yaitu pada ranah afekti, kognitf dan psikomotor. Salah satu ciri khas karakteristik Kurikulum 2013 di sekolah dasar adalah dengan memberlakukan pembelajaran alam bentuk tematik di setiap tingkatan kelas.

Pembelajaaran temaatik merupakan model pembelajaran bagian $\mathrm{d}$ ari pembelajaran tematik terpadu. Pembelajaran dengan menggabungkan satu atau lebih mata pelajaran yang kontennya saling berkaitan satu sama lain dalam suatu tema disebut dengan pembelajaran tematik. Yang mana dapat memberikan pengalaman yang bermakna pada siswa. Pembelajaran tematik pada Kurikulum 2013 ini disebut dengan pembelajaran tematik integratif karena pada pembelajaran tematik memiliki pendekatan yang berbeda dari pendekatan pembelajaran tematik pada kurikulum sebelumnya. Perbedaanya tampak pada pendekatan yang digunakan untuk mengintegrasi kompoetensi-kompetensi dasar dari bebragai mata pelajara ke dalam satu tema baikk secara intradisipliner, interdisipliner, multidisipliner dan transdisipliner berbagai mata pelajaran.Salah satu mata pelajaran yang 
terdapat dalam Kurikulum 2013 adalah mata pelajaran ilmu pengetahuan alam atau yang disingkat IPA.

IPA merupakaan usaha manusia yang dilakukan dalam memahamii alam melalaui kegiatam di mulai dari melakukan pengamatan, kegiatan yang sitematik dan terstuktur yang dapat dijelaskan secara rasional sehingga diperoleh suatu kesimpulan (Susanto, 2013). Proses pembelajaran IPA menekankan pada pemberian pengalamana langsung kepada siswa sehingga dapat memahami konsep dan menghayati seluruh kegaitan proses IPA, yang mana sangat verperan dalam meningkatkan mutu pendidikan (Fitria, 2017). Diberlakunya Kurikulum 2013 sebagai bagian dari penyempurnaan kurikulum yang bertujuan sebagai respon dalam menyikapi kebutuhan abad 21. Di mana yang sama-sama kita ketahui bahwa kompetensi abad 21 yaitu kemampuan dalam memanfaatkan teknologi informasi dan komuniaksi, kterampilan berpkir kritis, memecahkan masalah, kreatif, komunikatif dan berkolaborasi. Oleh sebab itu untuk menyikapi hal tersebut pelaksanaan pendidikan tidak bisa terlepas dari peran seorang pendidik.

Pendidikan merupakans alah bagian sangat penting. Jika pendidikan merupakan instrument utama pengemabangan sumber daya manusia, maka tenaga pendidik dalam hal ini guru memiliki tanggung jawab dalam pelaksanaan proses belajr mengajar menjadi lebih efisien. Guru merupakan unsur yang berperan penting dalam pelaksanaan proses pembelajaran. Melalui pendidikan guru, pelatihan guru dan pengembangan strategi pedagogi, guru dilatih dan dibimbing agar mempunyai bekal dalam mendidik siswanya (Cole, Ullman, Gannon, \& Rooney, 2015).

Guru adalah seseorang yang dapat menyatukan keterampilan intelektual yang paling dasar dan dapat diterapkan secara luas (Huang, Ricci, \& Mnatsakanian, 2016). Di mana peran guru adalah membantu siswa dalam belajar, baik kegiatan di dalam maupun di luar kelas. Peran guru terlihat dalam pembelajaran seperti memimpin diskusi di dalam kelas, menyiapkan materi pembelajaran, menjelaskan pembelajaran, mengevaluasi pembelajaran, mengoreksi hasil pembelajaran siswa, bersosialisasi baik dengan orang tuas siswa dan lain sebagainya (Loewenberg Ball \&
Forzani, 2009). Kemudian proses belajar mengajar akan menajdi lebih efisien di mana guru menajdi komponen terpenting dalam keberhasilan pendidikan dapat menggunakan strategi pembelajarn yang baik dan benar demi tercapainya tujuan pendidikan. Sebab penggunaan strategi pembelajaran dalam proses pmbelajaran brpengaruh trhadap hasil belajar siswa.

Preses pembelajaaran dalam kelas adalah kegiatan yang utama serta penting bagi siswa dan guru. Guru memiliki peran penting dalam melaksanakan pembelajaran di kelas. Kerena itu guru memegang peran penting sebagai penentu keberhasilam dalam suatu kegiatan belajar mengajar. Untuk itu penting penting mndesain rencana pelaksanaan belaajr.

Berbagai upaya dan usahan dilakukan oleh guru agar tujuan yang ingin dicapai dapat sampai kepada siswa, bisa dipahami dan dikuasai oleh siswa. Di mana guru sanagt berusaha agar terciptanya pembelajaran menyenangkankan, interaktif, inovatif, inspiratif dan dapat memotivasi siswa sehingga terwujudnya pembelajaran yang aktif dan mandiri. Yang dapat menaungi bakat, minat dan perkembangan siswa.

Namun, pada kenyataannya di lapangan pelaksanaannya terdapat beberapa kendala pun ditemukan, sehingga memunculkan berbagai macam kendalam dalam pelaksanaan belajar mengajar. Permasalahan yng muncul dalam pelaksanaannya seperti hasil belajarnya bermuatan IPA rendah. Belum tercapainya hasil belajaar yang memuaskan disebabkan oleh beberapa faktor. Seperti siswa belum aktif mengikuti proses pembelajaran, ketika guru menyampaikan materi, memeprhatikan guru, berbicara dengan teman sebangku, ada yang melamun dan diam saja, bercanda dengan teman, kurang fokus dan kurang antusias dalam belajar (Harjono, 2019).

Hasil belajar tematik yang memuat pelajaran IPA rendah juga disebabkan dikarenakan oleh pembelajaran IPA yang berjalan belum sesuai dengan yang diharapkan. Materi yang disampaikan cenderung materi hafalan diabndingkan dengan menalar atau melogikans sehingga terasa jenuh. Rendahnya hasil belajar siswa dengan materi yang bermuatan IPA, juga dikarenakan masih kurang kurangnya pada materi pembelajaran 
IPA, dan belum adanya penerapan model pembelajaaran yang cocok dan disesuaikan dengan materi pembelajaran. sedangkan guru juga terbatas dalam membuat dan menyiapkan media pembelajaran. Agar materi yang dismapaikan dapat tepat sasaran sesuai dengan yang diharapkan. Pemilihan model pembelajaran yang tepat dapat meningkatkan hasil belajar. Penggunaaan model pembelajarn yang sesuai dapat membangkit semangat dan motivasi belajar siswa (Pamungkas, Harjono, \& Airlanda, 2019)

Selain itu permasalahan lain yang muncul adalah mengenai penggunaaan dan penerapan model pembelajaran dalam pelaksanaan proses belajar mengajar (Zahroh, Setyawan, \& Citrawati, 2020). Jika menggunakan model pembelajaran kooperatif saja tanpa memikirkan tipe apa yang digunakan, tentu hasilnya belum maksimal. Guru hanya sekedar membagi siswa dalam bentuk kelompok-kelompok dan melakukan percobaan atau demonstrasi langsung tanpa meminta siswa memberikan pendapat apa maksud dari konsep pembelajaran yang sedang mereka lakukan, sehingga tidak ada pengalaman langsung yang diperoleh siswa. Yang mana pengalamaan langsung sangat penting bagi siswa agar terjadinya pembelajaran yang bermakna.

Oleh sebab itu, salah satu model pembelajaran yang dapat diterapkan untuk meminimalisir permaslaahan yang muncul pada pembelajaran, yang menyebabkan terjadinya rendahnya hasil pembelajaran siswa. Maka dari itu bisa digunakan model problem based learning yang merupakan model pembelajaran yang menggunakan kegiatan pembelajaran dengan pendekatan nyata. Model ini merupakan model pembelajaran yang mengajak siswanya untuk mampu memecahkan prmasalahan dan melibatkan siswa secara langsung menyeelsaikan masalah pada suatu kondisi yang ditemukannya (Harjono, 2019).

\section{DISCUSSIONS}

\section{Pembelajaran Tematik}

Membahas tentang hakikat pembelajaran tematik, hal terlebih dahulu kita ketahui di mualid ari pegertian pembelajaran. Pembelajaran merupakan usaha sadar yang dilakukan oleh guru untuk membelajarkan siswanya agar dapat mencapai tujuan yang diigninkan (Trianto, 2010). Seperangkat perencanaan pembelajaran di buat untuk melaksanakan proses belajar mengajar, yang mana dirancang untuk mendukung proses belajar siswa sehingga siswa mendapatkan pengalaaman langsung serta peningkatan hasil belajar (Saefuddin \& Berdiati, 2014). Jadi, dapat disimpulkan bahwa pembelajaran merupakan serangkaian kegiatan guru dan siswa yang memiliki hubungan timbal balik antara dalam situasi edukatif dalam mencapai tujaun pembelajaran yang diinginkan.

Sedangkan pemblajaran teamtik adalaah pembelajaran yang menggabungkn bebrapa pelajaran yang berkaitans atu sama lain yang digabungkan dalam satu tema pembelajaran (Utari \& Degeng, 2017). Pembelajaran tematik yang dirancang strategi yang digunakn untuk membelajarkan siswa pada sekolah dasar. Pembelajaran tematik cocok digunakan pada siswa sekolah dasar karena perkembangan kognitif siswa bersifat holistik.

Dalam pembelajaran tematik menyediakan keluasan dan keterpaduan antar mata pelajar yang memiliki isi atau konten yang saling berkaitan satu sama lain. Sehingga siswa tidak perlu lagi diajarkan dengan mata pelajaran yang terpisah. Dengan menerapkan pembelajaran tematik memunculkan penawaran yang dapat meningkatkan dinamika pendidikan sesuai dengan gaya belajaar dan prkembangan siswa.

\section{Pembelajaran IPA}

Ilmu penegtahuan alam merupakan bagian dari rumpun ilmu yang kajiannya merupakan benda yang ada di alam beserta dengan hukum-hukum yang berlaku (Wang, $\mathrm{Ho}, \& \mathrm{Fu}, 2019)$. IPA adaalh usaha manusia dalm memahamii alam smesta melalui observasi, menggunakan prosedural yang sistematik, dapat djelaskan dengan penalaran yang logis sehingga mendapatkan suatu kesimpulan (Ahmad Susanto, 2016). Hal-hal yang dipelajari adalah segala yang berhubgan dengan gejala alaam, dengan melakukan percobaan secara ilmiah dan dapat dibuktikan (Samatowa, 2011). 
Pengembangan IPA di mulai dari percabaan (induktif) kemudian pada perkembangans elanjutnya berdasarkan pada teori (deduktif). IPA dipandang sebagai pencarian dari rahasia alam, karena melalui penyelidikan, sehingga menghasilkan hasil penemuan. Yang mana dilakukan dari pengamatan yang sistematik dan menghasilkan kesimpulan yang bersifat umum dan terbuka (Wisudawati \& Sulistyowati, 2014).

Jadi, bisa kita simpulkan IPA adalh ilmu yang berhubungan dengan alam, yang disusun secara sistematis melaui percobaan dan pengamatan sehingga dapat memecahkan suatu masalah dan memperoleh hasil yang berlaku tidak hanya pada satu orang melainkan pada beberapa percobaan dengan hasil yang sama dan konsisten.

\section{Model Based Learning}

Problem based learning adalah model pmbelajaran berbasis masaalh pada kehidupan nyata dan mengajak siswa untuk bisa menyelesaikan masalah tersebut. Penerapan model pembelajaran ini dilakukan agar siwa terlibat aktif melalui beberapa tahapan-tahapan metode ilmiah sehingga siswa mendapatkan pengalaaman langsung dan mengembangkan keterampilan pemecahan masalah (Harjono, 2019).

Model PBL bertujuan agar siswa dapat melatih kemampuan berpikir kritisnya. Karena dengan disajikannya masalah, siswa akan terbiasa untuk berpikir dalam mencari solusi dari permasalahn yang dihadapinya. Sedangkan guru berperan sebagai faslitator dan pemberi araahan (Nurdyansyah, 2018).

Model PBL terdiri dari beberapa fasefase yaitu: 1) penyampaiaan msalah, 2) penususnan starategi, 3) penerapan startegi, 4) dan evaluasi (Anugraheni, 2018). Ciri-ciri dari model pembelajaran ini antara lains ebagai berikut : 1) Adanya masalah. Pembelajaran dengan menggunakan model problem based learning adaalh pembelajaran dengan mengorganisasikan pembejaran dengan berbasis masalah yang akan memberikan pengalaman dan pembelajaran yang bermakna bagi siswa. 2) Fokus pembelajarn sesuai dengn mata plajaran yang terkait. Pembelajaran berbasis masalah hendaknya bersifat autentik sehinga dapat dicari pemecahan msalahnya dari berbagai disiplin ilmu. 3) Autentik. Untuk memecahkan masalah siswa dituntuk untuk bisa melakukan percabaan, membuat hipotesis, melakukan eksperimen, membuat analisis dan membuat kesimpulan. 4) Produk. Hasil pengamaatn dalam bentuk laporan yang kemudian dipresentasikan (Nurdyansyah, 2018).

Tahapan dalam pelaksanaannya model problem based learning ini terdiri atas orientasi masalah, mengorgaisasikan siswa agar belajar aktif, membimbing penyelidikan siswa dalam kelompok, mengembangkan suatu karya, menganalisis, membuat evaluasi dari proses pemecahan masalah yang sudah dilakukan (Nurdyansyah, 2018).

Berdasarkan hasil penelitian yang telah ada, kemampuan berpikir kritis siswa dipenagruhi oleh model problem based learning (Wahyuni \& Anugraheni, 2020) dilihat dari hasil penelitian yang telah dilakukannya, nilai pre test mendapatkan rata-rata 62,86 dan nilai post test dengan rata-rata 74,83. Ini menunjukkan adanya pengaruh pada kemampuan berpikir kritis ssiwa setelah diberi perlakukan. Sejalan dengan hasil penelitian yang dilakukan oleh (Anugraheni, 2018) hasil analisis dari penelitiannya menunjukkan bahwa model PBL dapat meningkatkn kemampuan berpikir kritis siswa dari $2,87 \%$ sampai $33,56 \%$ dengan menunjukkan peningkatan yang signifikan sebesar $12,73 \%$.

(Janah, Widodo, \& Kasmui, 2018) yang mana pada model PBL memberikan kontibusi $35,00 \%$ terhadap hasil belajar siswa dan $19,36 \%$ pada keterampilan proses sains siwa. Sehingga diperolehlah model problem based learning berpengaruh trhadap hasil belajar dan keterampiilan proses siswa.

\section{CONCLUSION}

Pembelajaran merupakan serangkaian kegiatan siswa dan guru yang memiliki hubungan timbal balik yang brlangsung dalam situasi edukatif dalam mencapai tujaun pembelajaran yang diinginkan. Sedangkan pemblajaran tematik merupakn pembelajaran yang mengabungkan beberapa pelajaran yang berkaitans atu sama lain yang digabungkan dalam satu tema pembelajaran. 
IPA merupakan pelajaran yang termuat dan terjaring di dalam pembejaran tematik terpadu. IPA adalah ilmu yang berhubungan dengan alam dan kebendaan, yang disusun secara sistematis melaui percobaan dan pengamatan sehingga dapat memecahkan suatu masalah dan memperoleh hasil yang berlaku tidak hanya pada satu orang melainkan pada beberapa percobaan dengan hasil yang sama dan konsisten.

Problem based learning adalah model pmbelajaran berbasis masaalh yang ada pada kehidupan nyata dan mengajak siswa untuk bisa menyelesaikan masalah tersebut.

Berdasarkan analisis dari hasil penelitian yang telah dilakukan peneliti trdahulu, dapat diketahui model PBL berpengaruh terhadap kemampuan berpikir kritis siswa, hasil belajar dan keterampilan proses siswa.

Oleh sebab itu untuk pendidik maupun calon pendidik agar dapat menggunakan memilih dan menggunakan model pembelajaran yang sesuai dan dengan materi serta karakteristik siswanya. Sehingga dapat mewadahi berbagai macam gaya belajar, dan terjadi peningkatan pada hasil belajar.

\section{REFERENCES}

Ahmad Susanto, M. P. (2016). Teori belajar dan pembelajaran di sekolah dasar. Kencana.

Anugraheni, I. (2018). Meta Analisis Model Pembelajaran Problem Based Learning dalam Meningkatkan Keterampilan Berpikir Kritis di Sekolah Dasar [A Metaanalysis of Problem-Based Learning Models in Increasing Critical Thinking Skills in Elementary Schools]. Polyglot: Jurnal Ilmiah, 14(1), 9-18.

Cole, D. R., Ullman, J., Gannon, S., \& Rooney, P. (2015). Critical thinking skills in the International Baccalaureate's "Theory of Knowledge" subject: Findings from an Australian study. Australian Journal of Education, 59(3), 247-264.

Fitria, Y. (2017). Efektivitas capaian kompetensi belajar siswa dalam pembelajaran sains di sekolah dasar. Jurnal Inovasi Pendidikan Dan Pembelajaran Sekolah Dasar, 1(2).

Harjono, N. (2019). Peningkatan kemampuan berpikir kritis dan hasil belajar tematik muatan ipa melalui model problem based learning kelas $5 \mathrm{sd}$. Jurnal Basicedu, 3(1), 16-20.

Huang, H. F., Ricci, F. A., \& Mnatsakanian, M. (2016). Mathematical teaching strategies: Pathways to critical thinking and metacognition. International Journal of Research in Education and Science, 2(1), 190-200.

Janah, M. C., Widodo, A. T., \& Kasmui, K. (2018). Pengaruh model problem based learning terhadap hasil belajar dan keterampilan proses sains. Jurnal Inovasi Pendidikan Kimia, 12(1).

Loewenberg Ball, D., \& Forzani, F. M. (2009). The work of teaching and the challenge for teacher education. Journal of Teacher Education, 60(5), 497-511.

Nurdyansyah, N. (2018). Model Pembelajaran Berbasis Masalah Pada Pelajaran IPA Materi Komponen Ekosistem. Universitas Muhammadiyah Sidoarjo.

Pamungkas, G. H., Harjono, N., \& Airlanda, G. S. (2019). Peningkatan Proses dan Hasil Belajar IPA Kelas 5 Tema 6 Subtema 3 dengan Model Pembelajaran Discovery Learning. Jurnal Basicedu, 3(1), 43-46.

Saefuddin, A., \& Berdiati, I. (2014). Pembelajaran efektif. Bandung: Remaja Rosdakarya.

Samatowa, U. (2011). Pembelajaran IPA di sekolah dasar. Jakarta: PT indeks.

Susanto, A. (2013). Teori belajar dan pembelajaran di sekolah dasar. Jakarta: Kencana prenada media group.

Trianto, M. P. (2010). Mendesain Model Pembelajaran Inovatif-Progresif: Konsep, Landasan dan Implementasinya pada kurikulum Tingkat Satuan Pendidikan (KTSP). Jakarta: Kencana.

Utari, U., \& Degeng, I. N. S. (2017). Pembelajaran tematik berbasis kearifan lokal di sekolah dasar dalam menghadapi Masyarakat Ekonomi Asean (MEA). Jurnal Teori Dan Praksis Pembelajaran IPS, 1(1), 39-44.

Wahyuni, S., \& Anugraheni, I. (2020). Pengaruh Model Problem Based Learning Terhadap Kemampuan Berpikir Kritis Siswa Kelas IV Dalam Pembelajaran 
Tematik. Magistra: Jurnal Keguruan Dan Ilmu Pendidikan, 7(2), 73-82.

Wang, M.-H., Ho, Y.-S., \& Fu, H.-Z. (2019). Global performance and development on sustainable city based on natural science and social science research: A bibliometric analysis. Science of the Total Environment, 666, 1245-1254.

Wisudawati, A. W., \& Sulistyowati, E. (2014). Metodologi pembelajaran IPA. Jakarta: Bumi Aksara.

Zahroh, F., Setyawan, A., \& Citrawati, T. (2020). Studi Permasalahan dalam Pembelajaran Tematik Muatan IPA Kelas IV SDN Socah 4 Kabupaten Bangkalan. Prosiding Nasional Pendidikan: LPPM IKIP PGRI Bojonegoro, 1(1). 